Original Contribution

\title{
INFLUENCE OF SERUM MAGNESIUM ON MARKERS OF CALCIUM- PHOSPHORUS METABOLISM IN PATIENTS ON REGULAR HAEMODIALYSIS
}

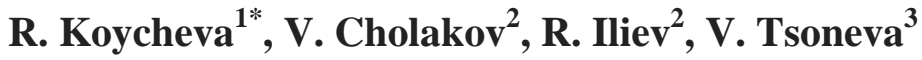 \\ ${ }^{1}$ Department of Nephrology, MHAT "Prof. Dr. Stoyan Kirkovich", Stara Zagora, Bulgaria \\ ${ }^{2}$ Department of Hemodialysis, MHAT "Prof. Dr. Stoyan Kirkovich", Stara Zagora, Bulgaria \\ ${ }^{3}$ Department Clinical Laboratory, MHAT "Prof. Dr. Stoyan Kirkovich", Stara Zagora, Bulgaria
}

\begin{abstract}
Secondary hyperparathyroidism is manifested early in the course of chronic kidney disease (CKD). Numerous studies have shown that serum magnesium significantly influences the function of the parathyroid glands. Serum levels of $\mathrm{Mg}$ in patients on regular hemodialysis were analyzed to establish their correlation with the levels of $\mathrm{Ca}, \mathrm{PO}_{4}$, Alkaline phosphatase (ALP) and intact parathyroid hormone (iPTH). A total of 72 test subjects ( 45 men and 27 women) were divided in two groups: 60 patients with diabetes mellitus and 12 patients without diabetes. Serum Mg levels were recorded immediately before and after intermediate weekly dialysis, using low-flux dialyzers with polysulfone membranes. Student`s ttest and linear regression analysis were used to analyze the available data. In both patient groups a significant disparity $(\mathrm{p}<0.005)$ was registered, confirming a positive correlation between serum $\mathrm{Mg}$ and serum total $\mathrm{Ca}, \mathrm{PO}_{4}, \mathrm{ALP}$ and urea reduction ratio (URR\%), much more pronounced with diabetic patients. A strong negative correlation between serum $\mathrm{Mg}$ and $\mathrm{iPTH}$ was observed. In patients with diabetes mellitus the average iPTH was $93,5 \pm 33.12 \mathrm{pg} / \mathrm{mL}, 41,6 \%$ of which have hypermagnesaemia in addition. In non-diabetics the average iPTH was $433.52 \pm 94.89 \mathrm{pg} / \mathrm{mL}$; hypermagnesemia was detected in $21,6 \%$ of the patients. Higher, compared to the normal levels, of serum magnesium was observed in almost twice as many diabetic patients on hemodialysis in comparison to reference values for iPTH patients on dialysis with stage 5 CKD, according to USA National Kidney Foundation's Kidney Disease Outcomes Quality Initiative (KDOQI). There is a discretely negative correlation between serum magnesium and iPTH, indicative of a suppressive effect of hypermagnesaemia on the synthesis and/or secretion of the parathyroid hormone.
\end{abstract}

Key words: magnesium, secondary hyperparathyroidism, chronic kidney disease, hemodialysis

\section{INTRODUCTION}

Secondary hyperparathyroidism is manifested early in the course of CKD and its progression is enhanced by the progress of renal impairment (1). It is the basis of uremic bone disease, vascular calcification and cardiovascular mortality in patients on haemodialysis. Hypocalcemia, hyperphosphatemia, impaired renal synthesis of 1,25- dihydroxyvitamin D3 with the concomitant reduction in serum

*Correspondence to: Dr. Reneta Koycheva, Department of Nephrology, MHAT "Prof. Dr. Stoyan Kirkovich” Stara Zagora, 2, General Stoletov Str., 6000 Stara Zagora, Bulgaria, e-mail: koychevar@abv.bg, GSM 0888990135 concentration of calcitriol and a reduced number of receptors for vitamin D, expressed on the surface of parathyroid cells are key components of the complex mechanism underpinning the secondary hyperparathyroidism (SHPT) and increased secretion of the parathyroid hormone (PTH) (2). Numerous studies indicate that serum magnesium definitely affects the function of the parathyroid glands.

Magnesium is part of more than 300 enzymatic and cellular reactions. Its role in the contraction of the cell cytoskeleton and holding myoneural impulses has an effect on skeletal and cardiac muscle functioning. It is the second most abundant intracellular cation: $67 \%$ of it is part of 
KOYCHEVA R., et al.

the bone tissue, $31 \%$ is intracellular and only 1$2 \%$ is in the extracellular space. Approximately $55 \%$ of the total extracellular $\mathrm{Mg}$ is free, ionized; $15 \%$ is bound to anions and about $30 \%$ - bound to albumin. Only by testing "ionized" magnesium can real deficiency (3) be diagnosed. $\mathrm{Mg}$ homeostasis depends on the balance between intestinal uptake (dietary intake) and renal excretion. In the kidney, magnesium is reabsorbed along with calcium, through paracellular uptake in the thick ascending limb of Henle. Active reabsorption of $\mathrm{Mg}^{2+}$ takes place in the distal convoluted tubule by specific channels and accounts for $10 \%$ of the total filtered load. The final urinary secretion of $\mathrm{Mg}^{2+}$ is determined in the distal convoluted tubule, where $\mathrm{Mg}^{2+}$ is being reabsorbed last. Although the presence of magnesium - sensitive hormone is biologically possible, there has been no published undeniable evidences. The serum level of magnesium is main regulator its metabolism (4). The connection between $\mathrm{Mg}$ and serum PTH is complex. PTH increases serum $\mathrm{Mg}$ by enhancing its intestinal absorption, bone resorption and renal reabsorption. On the other hand, $\mathrm{Mg}$ influences the synthesis, secretion and tissue sensitivity to PTH. Hypermagnesaemia, like hypercalcemia suppresses the PTH secretion, but its effect is 2,5-3 times lower than that of calcium (5). As renal excretion is the major route of elimination of $\mathrm{Mg}$, the end-stage of CKD is the only clinical condition where sustained hypermagnesaemia may occur and the net balance of magnesium is positive (6). It is possible, however, to achieve normal or even low levels. This could be attributed to the reduced dietary intake and intestinal absorption while in a state of uremia (6). In patients with stage 5 of CKD receiving dialysis (stage 5D of $\mathrm{CKD}$ ), serum $\mathrm{Mg}$ depends on the concentration of $\mathrm{Mg}^{2+}$ in the dialytic solution (7). With the decrease of renal function, the excretory capacity for $\mathrm{Mg}$ is significantly reduced. In stage 1-3 CKD with moderately reduced glomerular filtration rate, increased fractional excretion of $\mathrm{Mg}$ compensates for the loss of renal function and serum $\mathrm{Mg}$ levels are maintained within normal range. With the advance of CKD (stage 4-5), renal compensatory mechanisms become inadequate. Hypermagnesaemia is usually observed in patients with creatinine clearance below $10 \mathrm{ml} / \mathrm{min}$. In the case of patients on dialysis, the diffusion of $\mathrm{Mg}$ ions through dialysis or the peritoneal membrane, their concentration depending on the dialysate, is the main determinant of serum $\mathrm{Mg}$ levels (8). In recent years, the role of $\mathrm{Mg}$ in the calciumphosphorus metabolism has been studied and there are numerous reports that it influences the synthesis and secretion of iPTH, such as $\mathrm{Ca}^{2+}$ (9).

The main goals of this study were to: 1) analyse serum $\mathrm{Mg}$ concentrations in patients with stage 5D of CKD before and after dialysis and 2) establish the correlation between serum levels of $\mathrm{Mg}, \mathrm{Ca}, \mathrm{PO}_{4}, \mathrm{ALP}$ and $\mathrm{PTH}$ in patients undergoing regular haemodialysis.

\section{STATISTICAL ANALYSIS}

Detailed statistical analysis was performed using R (R Development Core Team 2013. R: a language and environment for statistical computing. Version 3.0.1. R Foundation for Statistical Computing, Vienna). Data are presented as mean \pm standard error of mean. The correlations between biochemical variables were calculated using Student t-test and Pearson correlation coefficient. The significance was set at the $p<0.05$ level.

\section{PATIENTS and METHODS}

72 patients on regular haemodialysis (45 men and 27 women) of average age of $56,3 \pm 1.79$ years were subjected to examination. They were divided into two groups - group A, with diabetes (12 patients in total, 6 men and 6 women, average age of $55.25 \pm 4.00$ years) and group B, without diabetes (60 patients, 39 men and 21 women of average age $56.58 \pm 2.00$ years). All patients undergo bicarbonate haemodialysis for at least 1 month. The mean dialysis times is 48.0 \pm 17.17 months for group A and $58.31 \pm 13.07$ months for group B. The dialysis solution used contained $\mathrm{Mg}$ - 0,50 mmol/l; with ionized $\mathrm{Ca}$ $1,75 \mathrm{mmol} / \mathrm{l}$ and $1,50 \mathrm{mmol} / \mathrm{l}$, depending on the serum $\mathrm{Ca}$ of each patient. Serum levels of $\mathrm{Ca}$, $\mathrm{PO}_{4}, \mathrm{Mg}$, ALP and iPTH were measured prior to regular weekly dialysis and specifically serum $\mathrm{Mg}$ levels immediately after dialysis. Low-flux dialyzers with polysulfone membranes were used. Serum $\mathrm{Ca}, \mathrm{PO}_{4}, \mathrm{Mg}$ and ALP were examined by test sets, as recommended by the International Federation of Clinical Chemistry (IFCC), while iPTH - by electrochemiluminiscent immunoassay (ECLIA). The efficiency of dialysis was rated as per the Urea Reduction Ratio\% (URR\%). The study was conducted in compliance with the recommended treatment comprising of Calcitriol, phosphate binder, vitamin $\mathrm{D}$ analogue and $\mathrm{Ca}$ mimetic, the dosage individually prescribed according to the severity of SHPT. Obtained results were 
KOYCHEVA R., et al.

statistically processed with Students t-test and linear regression analysis.

\section{RESULTS}

The demographic data and obtained before hemodialysis results are graphically presented in Table 1. Analyzed data refer to the levels of URR\%: $62.14 \pm 2.74$ for gr. A and $66.10 \pm 1.10$ for gr. B. Reference values for serum $\mathrm{Mg}$ vary between 0,70 to $1,05 \mathrm{mmol} / \mathrm{L}$. No significant variation was recorded in the average pre- and post-dialysis values of serum levels of $\mathrm{Mg}$ in patients with diabetes mellitus (gr. A) and patients without diabetes (gr. B) - 0,99 $\pm 0,06$ $\mathrm{mmol} / \mathrm{L}$ and $0,96 \pm 0,02 \mathrm{mmol} / \mathrm{L}, p$-non significant and $0,91 \pm 0,04 \mathrm{mmol} / \mathrm{L}$ and $0,89 \pm$ $0,01 \mathrm{mmol} / \mathrm{L}, p$ non significant respectively. When using a dialysis solution with a concentration of $\mathrm{Mg}^{2+}$ of $0,50 \mathrm{mmol} / \mathrm{L}$, an identical dynamic serum $\mathrm{Mg}$ level at the end of the dialysis session in both groups of patients was observed. By the end of the dialysis the minimum values were higher, the maximum lower. In all patients with diabetes mellitus, iPTH values did not exceed the recommended by KDOQI upper limit of $300 \mathrm{pg} / \mathrm{mL}$ for CKD stage $5 \mathrm{D}$, the average being $93,5 \pm 33.12 \mathrm{pg} / \mathrm{mL}$. $41,6 \%$ of them had in addition hypermagnesaemia and $\mathrm{iPTH}<120 \mathrm{pg} / \mathrm{mL}$. In the group of patients without diabetes mellitus, the average iPTH was $433.52 \pm 94.89 \mathrm{pg} / \mathrm{mL}$. Hypermagnesaemia is observed in only $21,6 \%$ of them, and $\mathrm{iPTH}<300 \mathrm{pg} / \mathrm{mL}$ was observed in $38,3 \%$. In both patient groups a significant disparity was recorded ( $\mathrm{p}<0.005)$, as well as a positive correlations between serum $\mathrm{Mg}$ with serum total $\mathrm{Ca}, \mathrm{PO}_{4}, \mathrm{ALP}$ and URR\%, much more pronounced in diabetic patients: $\mathrm{r}=0,64$; 0,46; 0,14 and 0,37 respectively (Figures 1-4).

Table 1. Demographic and laboratory findings in the study

\begin{tabular}{|c|c|c|c|c|c|c|}
\hline & \multicolumn{3}{|c|}{$\begin{array}{c}\text { Group A } \\
\text { Patients with diabetes } n=12\end{array}$} & \multicolumn{3}{|c|}{$\begin{array}{l}\text { Group B } \\
\text { Patients without diabetes } n=60\end{array}$} \\
\hline & Min & Max & $\begin{array}{l}\text { Mean } \pm \\
\text { SEM }\end{array}$ & Min & Max & Mean \pm SEM \\
\hline Age (years) & 30 & 74 & $55,3 \pm 4.00$ & 13 & 81 & $56.5 \pm 2.00$ \\
\hline $\begin{array}{c}\text { Hemodialysis } \\
\text { duration } \\
\text { (months) }\end{array}$ & 3 & 212 & $48.0 \pm 17.17$ & 1 & 195 & $58.31 \pm 6.53$ \\
\hline URR\% & 49.9 & 77,6 & $62.14 \pm 2.74$ & 34.03 & 80,9 & $66.1 \pm 1.10$ \\
\hline iPTH $(\mathrm{pg} / \mathrm{mL})$ & 18,9 & 207 & $93,5 \pm 33.12$ & 22 & 2889 & $433.52 \pm 94.89$ \\
\hline $\mathrm{Ca}(\mathrm{mmol} / \mathrm{L})$ & 1,37 & 2,71 & $2,16 \pm 0,11$ & 1,43 & 3,02 & $2,16 \pm 0,04$ \\
\hline $\mathrm{PO}_{4}(\mathrm{mmol} / \mathrm{L})$ & 0,87 & 2,87 & $2,07 \pm 0,18$ & 0,88 & 6,97 & $2.44 \pm 0,12$ \\
\hline ALP (mmol/L) & 59 & 265 & $118 \pm 17.05$ & 46 & 1520 & $147 \pm 27,01$ \\
\hline $\mathrm{Mg}(\mathrm{mmol} / \mathrm{L})$ & 0,59 & 1,27 & $0,99 \pm 0,6$ & 0,69 & 1,32 & $0,96 \pm 0,15$ \\
\hline
\end{tabular}

In group A pronounced negative correlation between serum Mg and iPTH $(p<0.05 r=-0,90)$ was established, whereas in group B (without DM) - a weak positive correlation was registered - $r=0,29$ (Figures 5 and 6).

\section{DISCUSSION}

Our research determined a significant disparity in both groups of patients $(\mathrm{p}<0.005)$ and a notable correlation between serum $\mathrm{Mg}$ with serum total $\mathrm{Ca}, \mathrm{PO}_{4}, \mathrm{ALP}$ and URR\%, which is more pronounced in patients with diabetes. A definite negative correlation between serum $\mathrm{Mg}$ and $\mathrm{IPTH}$ was observed, as well. Serum $\mathrm{Mg}$ in relation to iPTH levels investigated so far by other scientists show similar results (10). The study of Gonda et al. in 86 hemodialysis patients established the negative correlation between serum $\mathrm{PPTH}$ and $\mathrm{Mg}$ and the authors conclude that serum $\mathrm{Mg}$ can be used to predict expected levels of PTH(11). In a large study of 110 patients on hemodialysis, Navarro et al., found that the serum levels of $\mathrm{Mg}$ are inversely correlated with the iPTH, as it is influenced by the level of $\mathrm{Mg}$. Patients with inadequately low level of PTH have higher serum $\mathrm{Mg}$, suggesting that chronic hypermagnesaemia may inhibit the synthesis and/or secretion of PTH(12). The same 
Correlation between serum $\mathrm{Mg}$ and $\mathrm{Ca}$ $r=0,64$

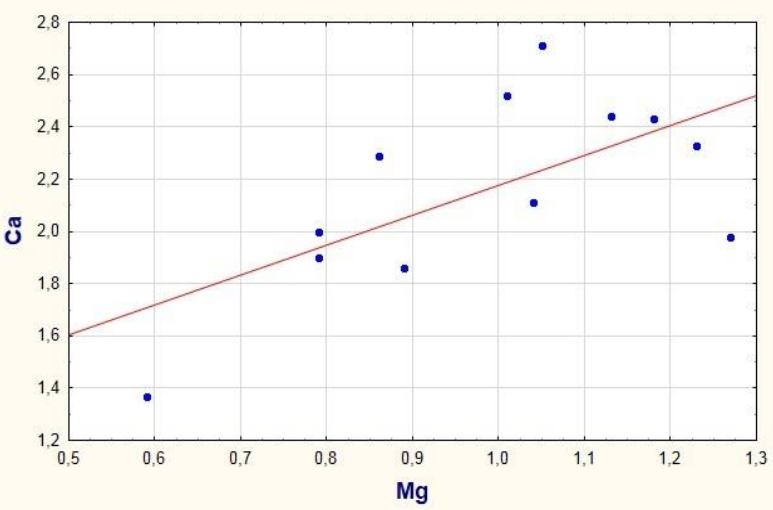

Figure 1.

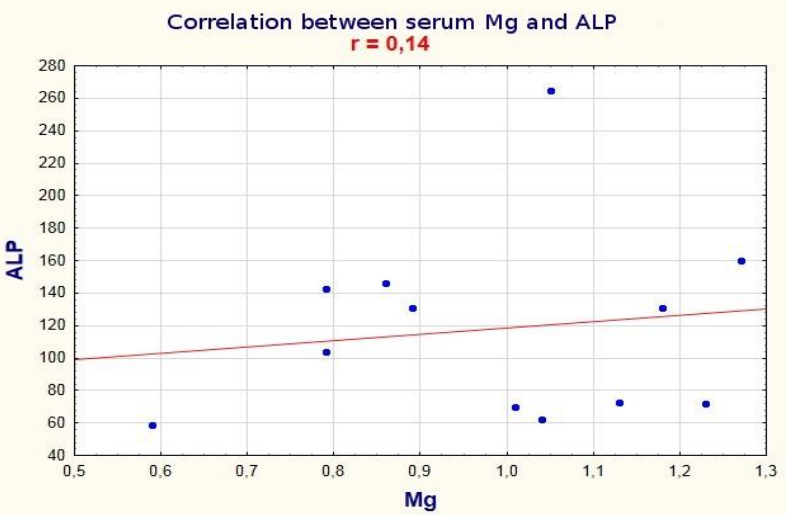

Figure 3.

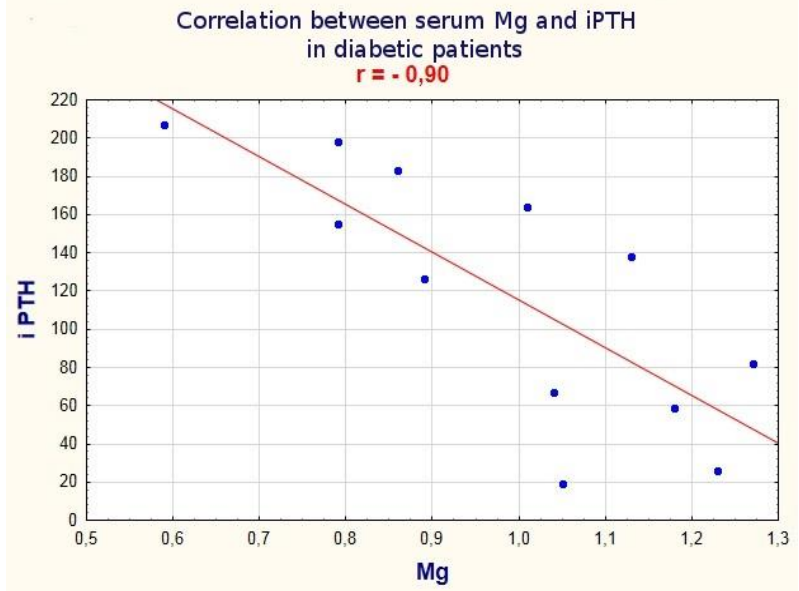

Figure 5.

author noted that this mutual influence is manifested regardless of other factors, as a result regulating the function of the parathyroid glands (calcium, phosphate and vitamin D) in both patients on hemodialysis and on peritoneal dialysis (13). Important research data were obtained for patients with diabetic nephropathy at the stage of CKD 5D. It is well known that such patients have a lower iPTH count in comparison to non-diabetics at this specific stage of $\mathrm{CKD}(14)$. There are several explanations for

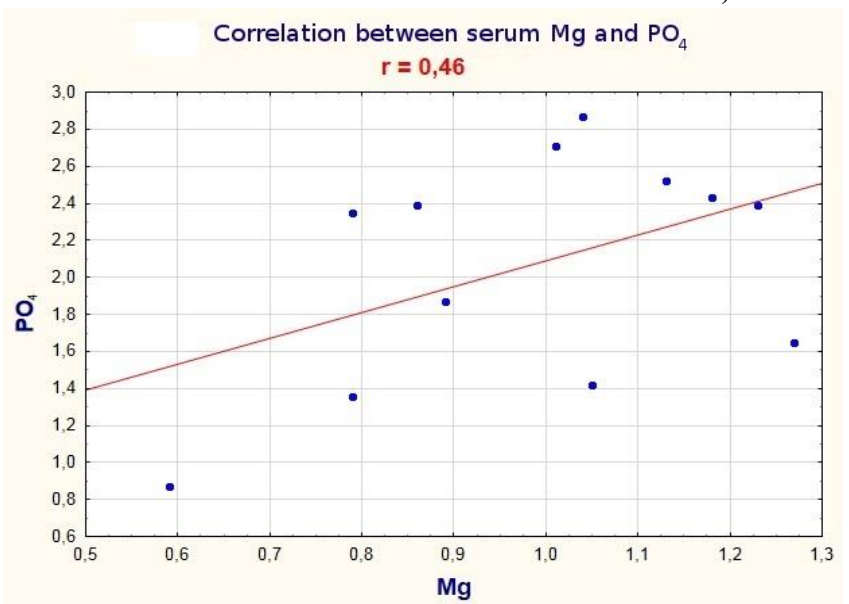

Figure 2.

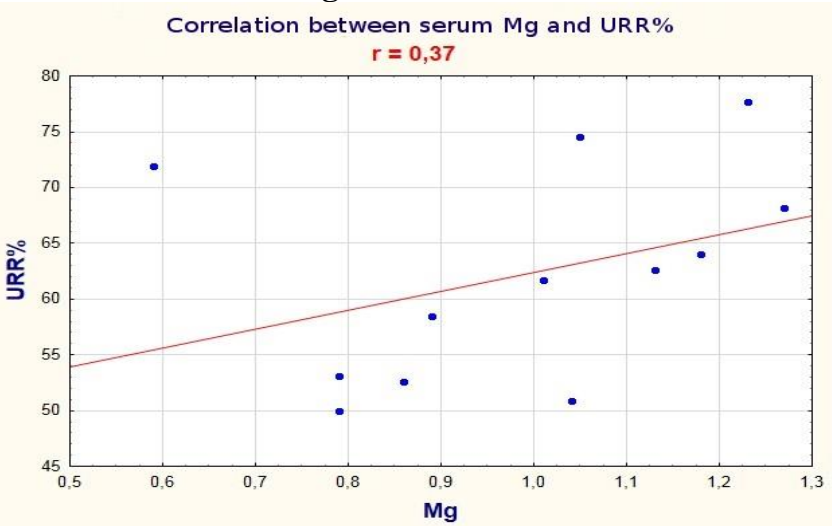

Figure 4.

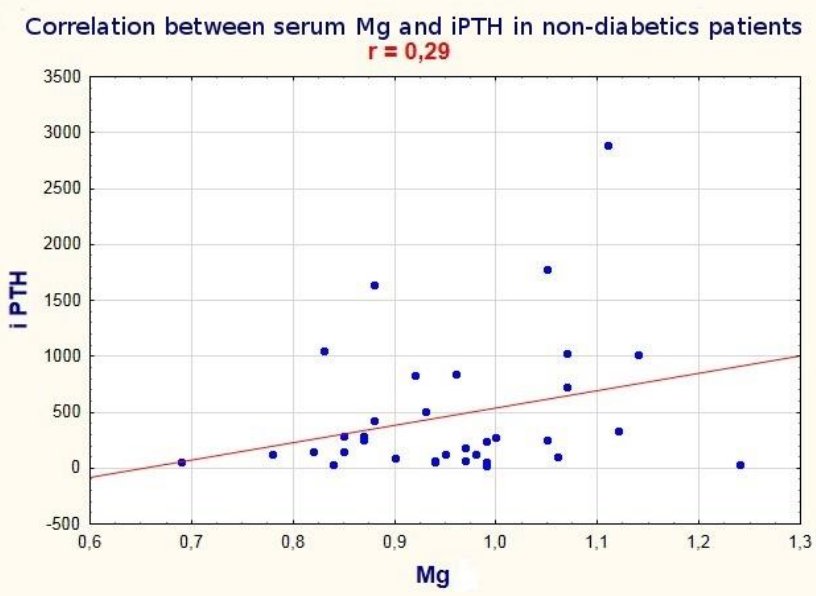

Figure 6.

these results. Studies with bovine parathyroid cell cultures established suppression of parathyroid hormone secretion in conditions of excess glucose or insulin deficiency (15). In patients with diabetes and CKD inverse correlation was registered between blood sugar levels and iPTH decrease in creatinine clearance below $70 \mathrm{ml} / \mathrm{min}$. This dependence becomes more prominent as renal function worsens; only i.e. hyperglycaemia has an inhibitory effect on the synthesis and secretion of iPTH (16). 
Patients with DM usually have hypermagnesaemia. Thus, the two conditions mutually and independently suppress the parathyroid function. However, in diabetics may lessen the effect of PTH. Therefore, it can be considered that hyperglycaemia with insulin deficiency has a protective effect on the development of hyperparathyroidism. On the other hand, it leads to a hypoparathyroid condition, triggering a reduced bone turnover (adinamic bone disease). Our study confirmed the role of hypermagnesemia as an inhibitor of the synthesis of PTH. Registered lower levels of $\mathrm{iPTH}<120 \mathrm{pg} / \mathrm{mL}$ are a precondition for the manifestation of adinamic bone disease in these patients.

\section{CONCLUSIONS}

Serum magnesium is elevated in a significant number of patients with diabetic nephropathy with end-stage CKD. All these patients have a relatively pronounced hypoparathyroidism. There is a strong negative correlation between serum $\mathrm{Mg}$ and $\mathrm{IPTH}$, indicating that hypermagnesaemia has suppressive effect on the synthesis and /or secretion of the parathyroid hormone. High serum $\mathrm{Mg}$ levels, especially in patients with diabetes mellitus in CKD stage 5D, is both an indication and a trigger causing the adynamic bone disease. The use of dialysis solution with concentration of $\mathrm{Mg}^{2+} 0,50 \mathrm{mmol}$ $/ \mathrm{L}$ results in normomagnesaemia at the end of the dialysis procedure.

\section{REFERENCES}

1. Jonova, D. Risk factors for the development of vascular calcification in patients on dialysis - Med.pregled, 40, № 2, 24-27, 2004.

2. Jonova, D. C-reactive protein - some diagnostic applications. - Nephrons. Hemodial. Transpl, № 4, 9-11, 2003.

3. Innerarity S. Hypomagnesemia in acute and chronic illness. Crit Care Nurs Q, 23:1, 2000.

4. Wagner CA. Disorders of renal magnesium handling explain renal magnesium transport. J Nephrol, 20:507, 2007.

5. Kanbay M, Goldsmith D, Uyar ME et al. Magnesium in Chronic Kidney Disease:
Challenges and Opportunities. Blood Purif 29:280-292, 2010.

6. Mountokalakis TD. Magnesium metabolism in chronic renal failure. Magnes Res, 3(2):121-7, 1990.

7. Kelber J, Slatopolsky E, Delmez JA. Acute effects of different concentrations of dialysate magnesium during high-efficiency dialysis. Am J Kidney Dis, 24:453-60,1994.

8. de Francisco ÁLM, Rodríguez $M$. Magnesium - its role in CKD. Nefrologia, 33(3): 389-99, 2013.

9. Guh JY, Chen HC, Chuang HJ et al. Risk factors and risk for mortality of mild hypoparathyroidism in hemodialysis patients. Am J Kidney Dis, 39(6): 1245-54, 2002.

10. Wei M, Esbaei $\mathrm{K}$, Bargman $\mathrm{J}$ et al. Relationship between serum magnesium, parathyroid hormone and vascular calcification in patients on dialysis: A literature review. Perit Dial Int, 26, 366373, 2006.

11. Gonda T, Shou I, Fukui M et al. Parathyroid hormone gene polymorphism and secondary hyperparathypoidism in hemodialysis patients. Am J Kidney Dis 39(6): 1255-60, 2002.

12. Navarro JF, Mora C, Jiménez A et al. Relationship between serum magnesium and parathyroid hormone levels in hemodialysis patients. Am J Kidney Dis, Jul;34(1): 43-8, 1999.

13. Navarro JF, Mora C, Garcia J. Serum magnesium and parathyroid hormone levels in dialysis patients. Kidney Int. 57: 2654, 2000.

14. Vicenti F, Arnaud SB, Recker $\mathrm{R}$ et al. Parathyroid and bone response of the diabetic patients to uremia. Kidney Int, 25: 677-682, 1984.

15. Sugimoto T, Ritter C, Morrissey J, Hayes C, Slatopolsky E. Effects of high concentrations of glucose on PTH secretion in parathyroid cells. Kidney Int 37: 15221527, 1990.

16. Martınez I, Saracho R, Moina I et al. Is there a lesser hyperparathyroidism in diabetic patients with chronic renal failure? Nephrol Dial Transplant, 13: [Suppl 3]: 911, 1998. 